$1 N-20$

NASA Technical Memorandum 105547

79830

$p-1$

\title{
Nuclear Electric Propulsion Technology Panel Findings and Recommendations
}

Michael P. Doherty

National Aeronautics and Space Administration

Lewis Research Center

Cleveland, Ohio

Prepared for the

Ninth Symposium on Space Nuclear Power Systems

Albuquerque, New Mexico, January 12-16, 1992 


\author{
NUCLEAR ELECTRIC PROPULSION TECHNOLOGY PANEL \\ FINDINGS AND RECOMMENDATIONS \\ Michael P. Doherty \\ National Aeronautics and Space Administration \\ Lewis Research Center \\ Cleveland, Ohio 44135
}

\begin{abstract}
Summarized in this paper are the findings and recommendations of a triagency (NASA/DOE/DOD) panel on Nuclear Electric Propulsion (NEP) Technology. NEP has been identified as a candidate nuclear propulsion technology for exploration of the Moon and Mars as part of the Space Exploration Initiative (SEI). The findings are stated in the areas of system and subsystem considerations, technology readiness, and ground test facilities. Recommendations made by the panel are summarized concerning (1) existing space nuclear power and propulsion programs and (2) the proposed multiagency NEP technology development program.
\end{abstract}

\title{
INTRODUCTION
}

The Stafford "Synthesis Committee" has suggested that nuclear propulsion will be required to safely, cheaply, and repeatedly conduct high performance Space Exploration Initiative (SEI) space missions (Synthesis Group 1991). The technology to perform these nuclear propulsion space missions with either Nuclear Electric Propulsion (NEP) or Nuclear Thermal Propulsion (NTP) must be developed and validated.

Six interagency technical panels comprised of National Aeronautics and Space Administration (NASA), Department of Energy (DOE), and Department of Defense (DOD) personnel were formed in FY91 to address mission analysis, safety, facilities, and technology development requirements for Nuclear Propulsion (NP) for advanced SEI space missions (Clark and Miller 1991). The panels met approximately monthly. Direction was provided and progress monitored by a Nuclear propulsion steering committee consisting of program managers from the three organizations.

The Nuclear Electric Propulsion (NEP) Technology Panel was chartered to characterize NEP system and technology options in light of mission and safety considerations, and to initiate the planning for a NEP technology development program. The goals of the NEP Technology panel were to provide a basis for evaluating candidate power/propulsion systems, to identify nuclear and nonnuclear technology needs and plans, to define the major facility requirements for NEP, and to establish requirements for a NEP systems trade study. Twenty-one technical experts in nuclear 
reactor systems; power conversion, conditioning and processing; space systems engineering; and electric thruster technology were formed into working subpanels to achieve these goals. A summary final report is being prepared for publication (Doherty and Holcomb 1992).

Three broad classes of missions are being considered for NEP systems :

* Near Earth, such as orbit transfer, maneuvering, and station keeping;

* Planetary Exploration, such as robotic probes to the outer planets, comet nucleus sample return, asteroid exploration, and others; and

* Space Exploration Initiative, such as lunar cargo missions, and Mars cargo and piloted missions, including short trip time missions.

In addressing these three broad classes of missions, NEP subsystem technology options shown in Table 1 must be considered. This table includes all of the power and propulsion concepts discussed by Barnett (1991). To validate the required NEP technologies, programs must be initiated or focused in

TABLE 1. NEP Subsysten Technology Options.

\begin{tabular}{|c|c|c|c|c|}
\hline Reactor & $\begin{array}{c}\text { Power } \\
\text { Conversion }\end{array}$ & $\begin{array}{l}\text { Thermal } \\
\text { Management }\end{array}$ & $\begin{array}{l}\text { Power Management } \\
\text { \& Distribution }\end{array}$ & Thruster \\
\hline $\begin{array}{l}\text { Liquid Metal } \\
\text { Cooled } \\
\text { Growth SP-100 } \\
\text { Advanced Pin } \\
\text { Cermet } \\
\text { Boiling } \\
\text { Potassium } \\
\text { Gas Cooled } \\
\text { NERVA Derived } \\
\text { Particle Bed } \\
\text { Pebble Bed } \\
\text { Cenmet }\end{array}$ & $\begin{array}{l}\text { Dynamic } \\
\text { Rankine } \\
\text { Brayton } \\
\text { Stirling } \\
\text { Static } \\
\text { Thermoelectric } \\
\text { Thermionic } \\
\text { in core } \\
\text { ex core } \\
\text { Electrochemical } \\
\text { Magnetohydro- } \\
\text { dynamic } \\
\text {. }\end{array}$ & $\begin{array}{l}\text { Heat Pipe } \\
\text { Refractory Metal } \\
\text { Carbon-carbon } \\
\text { Ceranic Fabric } \\
\text { Pumped Loop } \\
\text { Liquid Sheet/ } \\
\text { Droplet } \\
\text { Bubble Membrane }\end{array}$ & $\begin{array}{l}\text { Silicon } \\
\text { Gallium Arsenide } \\
\text { Aluminum-Gallium } \\
\text { Arsenide } \\
\text { Silicon Carbide }\end{array}$ & $\begin{array}{l}\frac{\text { Steady State }}{\text { Electrostatic }} \\
\text { Ion } \\
\text { Steady State } \\
\text { Electromagnetic } \\
\text { Magnetoplasma- } \\
\text { dynamic (MPD) } \\
\text { Electron Cyclotron } \\
\text { Resonance } \\
\text { Ion Cyclotron } \\
\text { Resonance } \\
\text { Variable Specific } \\
\text { Impulse }\end{array}$ \\
\hline $\begin{array}{l}\text { Incore } \\
\text { Thermionic }\end{array}$ & & & & $\begin{array}{l}\text { Pulsed Electromagnetic } \\
\text { Deflagration } \\
\text { Pulsed Plasmoid } \\
\text { Pulsed Inductive }\end{array}$ \\
\hline Vapor Core & & & & $\begin{array}{l}\text { Pulsed Electrothermal/ } \\
\text { Electromagnetic } \\
\text { Pulsed Electrothermal } \\
\text { - MPD }\end{array}$ \\
\hline
\end{tabular}


reactor systems and fuels; power conversion, conditioning and processing; heat rejection and thermal management; and electric thrusters, with the goal of ground testing these subsystems prior to their use in outer space. Technology drivers are low mass, high reliability, and long life subsystems and systems.

\section{PANEL FINDINGS \& CONCLUSIONS}

The NEP Technology Panel reached a number of findings and conclusions. These can be grouped under the headings of system and Subsystem Considerations, Technology Readiness, and Ground Test Facilities.

\section{System and Subsystem Considerations}

NEP has the potential to implement a broad range of mission applications, starting from near Earth and planetary exploration missions, and proceeding to SEI Lunar and Mars missions. Successfully addressing these missions will require evolutionary increases in net on-board electrical power for propulsion and measured decreases in system specific mass. System and subsystem considerations follow.

\section{Systems}

NEP systems which address the requirements for this broad range of missions will likely have many common technologies. For example, the SP-100 reactor and fuel technology currently being developed for space power applications potentially offers benefit to all the missions discussed. Also, dynamic power conversion technology, such as Potassium Rankine (K-Rankine) or Brayton, enabling for cargo missions, is the same technology necessary for piloted missions. Likewise, the Ion electric thruster, although not as physically compact as the Magnetoplasmadynamic (MPD) thruster, has a strong history of technology development, making it a candidate for the SEI missions, as well as for near Earth and planetary exploration missions.

For application to a propulsion system for planetary robotic missions, the SP-100 reactor and thermoelectric power conversion technologies, in combination with ion electric propulsion technology, seem well suited. Yen and Sauer (1991) show that timely development of these technologies offers a significant means to conduct rewarding robotic science missions in the early 21 st century. Thermionic reactors offer promise for this application also. Such robotic missions are logical technology precursors to the higher power SEI missions.

Because NEP has the potential to implement a broad range of advanced space missions, and there is a host of candidate technologies, there is a need to perform a detailed systems/ subsystems trade study to determine optimum combinations of those technologies. This activity will provide a reference point for the initiation of detailed technology programs, and therefore is 
vital to conduct in the early program years for NEP.

Subsystems

The SP-100 reactor and fuel technology may be applicable to piloted missions to Mars. Recent mission and system studies (Hack et al. 1991) and (George 1991) have shown that this pintype fuel, operating at higher temperatures in a larger core reactor, coupled to a K-Rankine power conversion system, with high temperature power management and distribution, lightweight heat pipe radiators, and ion electric thrusters, can propel a vehicle to Mars and back with trip times competitive with NTP systems at values of initial mass in low Earth orbit (IMLEO) somewhat less than NTP.

If greater performance is sought, more advanced reactor and power conversion technologies would be required (George 1991). Such an advanced system might be: 1) a $1500 \mathrm{~K}$ outlet temperature advanced pin-type liquid metal cooled reactor with K-Rankine power conversion, 2) a $2000 \mathrm{~K}$ outlet temperature gas cooled particle bed reactor with direct Brayton power conversion, or 3) an innovative design such as a gas (vapor) core reactor with Magnetohydrodynamic (MHD) conversion.

K-Rankine power conversion technology, in combination with SP100 reactor technology, yields a lighter overall system mass than Brayton. Due to its higher cycle temperature ratio, Brayton cycle power conversion technology requires higher peak cycle temperatures than achievable with a $1375 \mathrm{~K}$ thermal source to result in a system mass competitive to $\mathrm{K}$-Rankine. Therefore, given current SP-100 reactor technology, K-Rankine power conversion technology promises higher system performance.

Heat rejection subsystems for NEP must be lightweight, employing lightweight, high temperature materials. As the heat rejection subsystem mass is a dominant portion of the total NEP system mass, the performance of the heat rejection subsystem directly affects the overall performance of the system. Power Management and Distribution (PMAD) subsystems must be capable of high temperature, efficient operation, so that waste heat rejection can be accomplished using small radiator systems. High PMAD efficiency reduces both thermal and power system mass. As for electric thrusters, they must be efficient and be capable of long lifetimes.

\section{Technology Readiness}

The panel judged the NEP subsystem technology options according to their projected technology readiness. Table 2 displays the projected readiness of those technology options in Table 1 that would apply to the SEI missions. Within Table 2, any of the options listed in the middle column could be ground tested in a relevant environment - Technology Readiness Level 5 (TRL-5) - by the year 2005 (with adequate funding) and have been classified as 
TABLE 2. Projected Technology Readiness of NEP Subsystem Technology Options Applicable to SEI Missions.

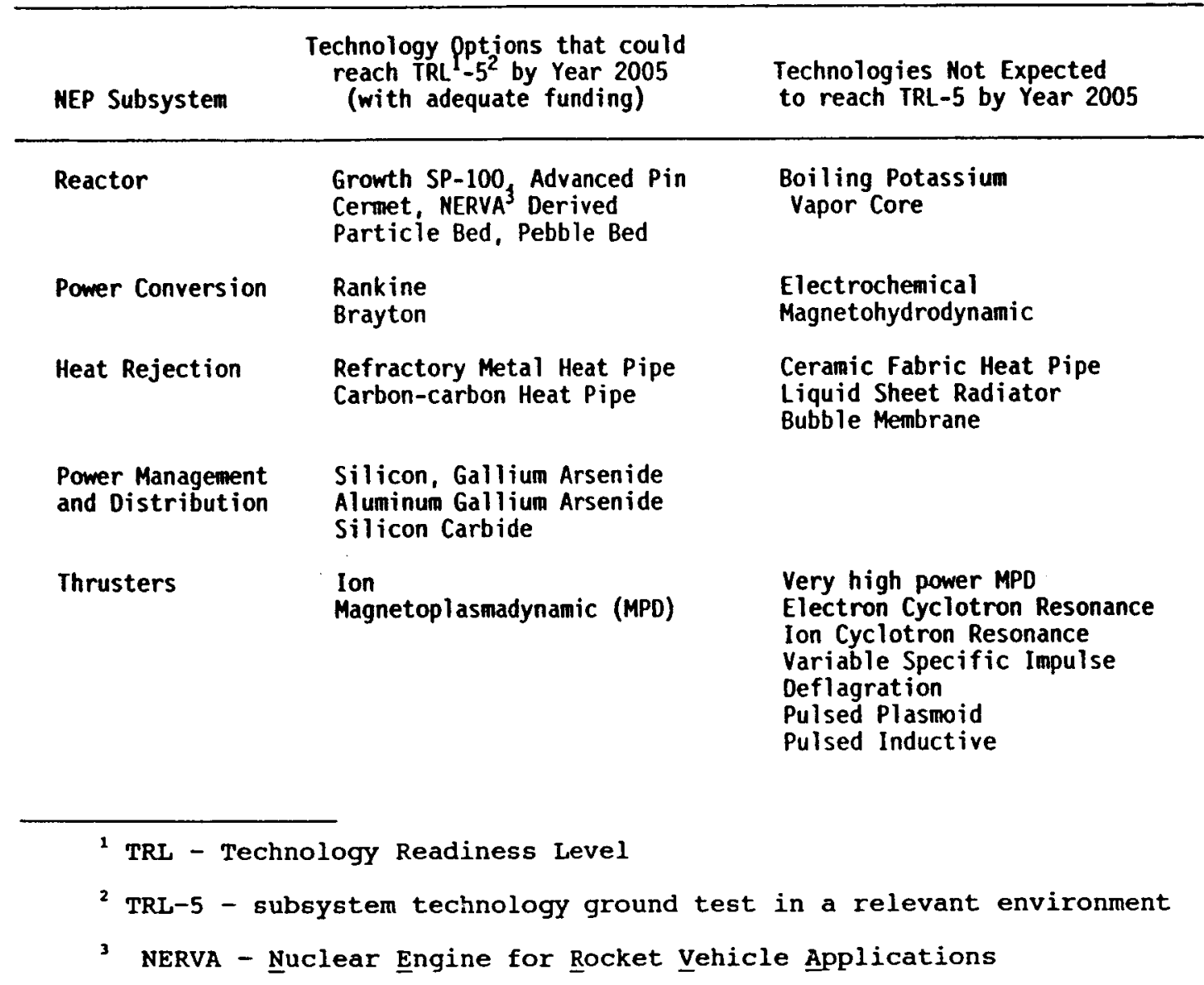

enabling for the SEI missions. Those options not expected to reach TRL-5 by 2005 are listed in the right-hand column of this table, and have been classified as "innovative". The year 2005 was chosen so that the technologies would be available in time to be considered for the SEI missions.

K-Rankine and Brayton based power systems are the recommended choices for SEI applications in the 2008-2020 timeframe, which require TRL-5 by 2001-2010. Other power system concepts are either suitable only for NEP applications requiring less power, or are presently deemed to have benefit-to-risk ratios too low as to expect their readiness in this timeframe (innovative). All of the reactor concepts 1 isted in the middle column of Table 2 are relevant to Rankine and Brayton based power systems.

Rankine cycle space power conversion has many technological challenges to overcome. Challenges include turbine blade erosion due to vapor condensation, and condensate collection, management, and transport in a micro-gravity environment. Brayton cycle power conversion, on the other hand, is well understood and presents fewer technology issues. 
Ion and MPD propulsion systems are the recommended choices for SEI applications in the 2008-2020 timeframe, requiring TRL-5 by 2001-2010. Ion propulsion is more mature than MPD propulsion, but has the disadvantage of being less power dense, requiring large thruster areas to accomplish the SEI missions. MPD, while being compact and having demonstrated high power operation, must show suitable efficiences. Both propulsion technologies must demonstrate acceptable life. Other propulsion system concepts are either suitable only for applications requiring less specific impulse, or are presently deemed to have benefit-to-risk ratios too low as to expect their readiness in this timeframe

(innovative). If further studies indicate an advantage to developing any of these technologies, and feasibility issues have been resolved, then with adequate funding any of these technologies could be made available within the needed timeframe.

Pin-type fuels should be given the highest priority in the NEP fuels development program. The current sp-100 fuel pin design, Uranium Nitride (UN) pellets enclosed in PWC-11 clad tubing, should be irradiation tested at higher fuel temperatures (to 1500 $\mathrm{K})$ to uncover fuel integrity issues associated with shorter life, higher temperature mission demands. Higher temperature cladding candidates for UN pin-type fuels should also be screened, and irradiation tests of these potential fuels performed.

Fabrication and capsule irradiation tests of cermet and carbide fuels should be initiated if mission and system studies show significant benefit. Bhattacharyya et al. (1991) provide more discussion on the development of nuclear fuels for propulsion systems for SEI.

\section{Ground Test Facilities}

NEP technology will be validated at the subsystem level (TRL5). There are two reasons for this. First, because there is only an electrical coupling between NEP power and propulsion subsystems, each subsystem should be capable of being adequately simulated in the testing of the other. That is, an electrical load simulating the electric thruster and power processing subsystems could be used in the NEP power subsystem test, and vice versa. Second, test environments for space power and space propulsion subsystems are very different from one another. Space power subsystems require a clean, static thermal vacuum environment, while the test environment for electric thrusters is characterized by the presence of an effluent. These requirements, in combination with the extreme distances between reactor and thruster subsystems to minimize radiation effects, place severe demands on a facility to test "everything under one roof". Flight system demonstrations from orbit about Earth, first using low power NEP systems for orbit raising missions, then larger NEP systems for planetary missions, and finally MWclass NEP systems for SEI cargo missions should provide the necessary system and flight experience to assure reliable performance of the piloted NEP system. The major facility requirements for validating NEP technology to TRL-5 are presented 
in Table 3.

TABLE 3. Major Facility Requirements for Ground Testing NEP Subsystem Technologies in a Relevant Environment.

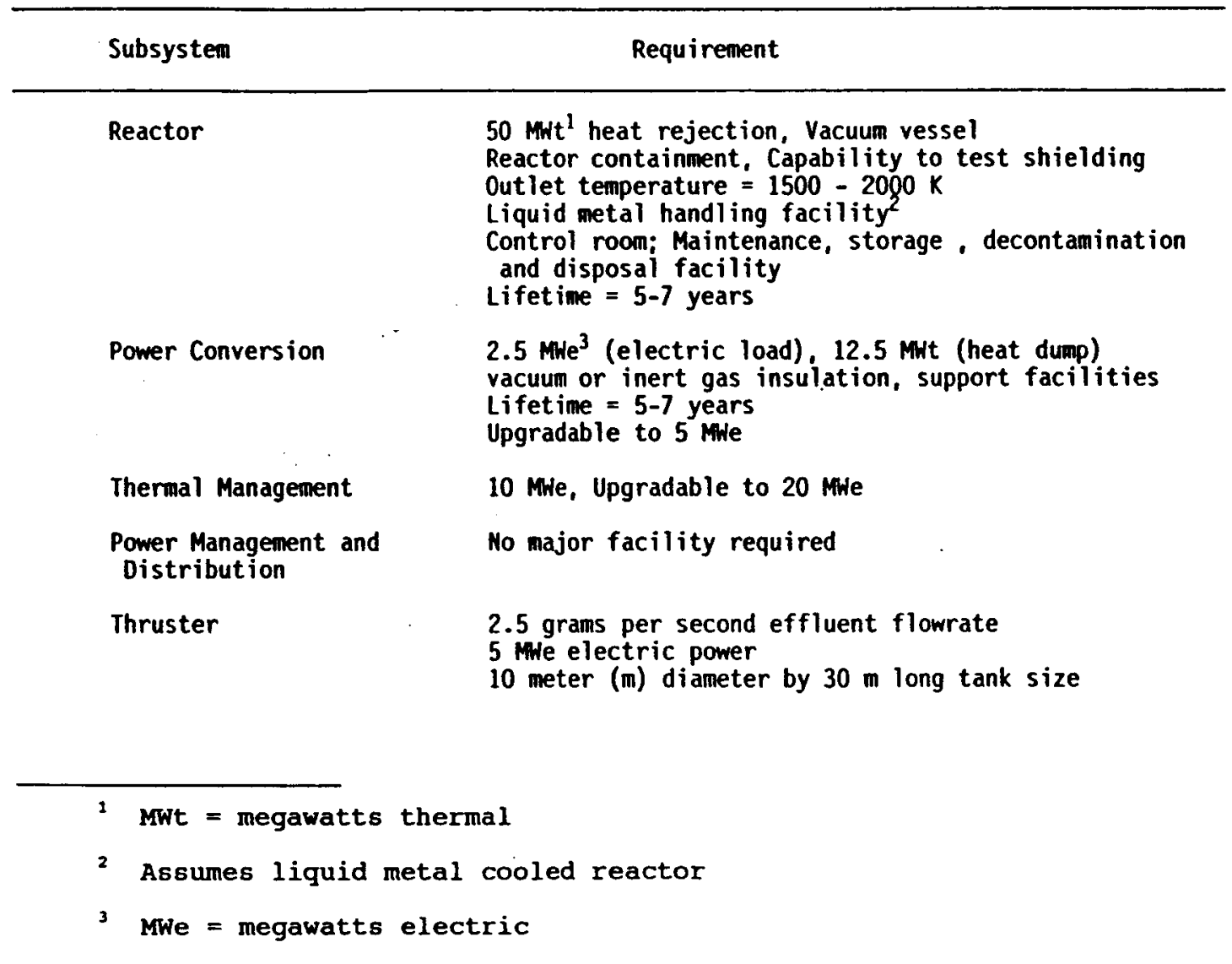

\section{PANEL RECOMMENDATIONS}

In view of the above panel findings and conclusions, the following recommendations concerning NEP and a technology development program in Nuclear Electric Propulsion are made:

* NASA should plan and implement an evolutionary technology development program in NEP, a program directed toward providing the technologies for a piloted mission to Mars, while also including interim program milestones which yield NEP technologies for near Earth, interplanetary robotic, as well as lunar and Mars cargo missions;

* From the program outset, efforts should be initiated to (1) determine performance and life limits of $\mathrm{kW}-\mathrm{class}$ and $\mathrm{MW}-\mathrm{class}$ electric thrusters, (2) determine efficiencies, lifetimes, and radiation tolerance of high-temperature power electronics, and (3) address fundamental technology issues associated with lightweight heat rejection systems; 
* Accelerate the schedule for a ground test demonstration of the SP-100 space reactor and power conversion technologies in the late 1990s;

* Perform a systems/ subsystems trade study early in the program to clarify critically needed technology programs and to specify detailed technology requirements for system safety and performance;

* Demonstrate high power, dynamic power conversion technologies;

* If justified by systems trade studies, develop and demonstrate a new reactor technology;

* Demonstrate the current SP-100 fuels technology (UN with PWC-1I clad tubing) at higher temperature operating conditions to identify technological feasibility of the concept;

* Assess candidate facilities for power subsystem and propulsion subsystem testing for their suitability to meet ground testing requirements; and

* Provide a forum for the continued involvement of experts in all technology areas of NEP as the program is implemented.

\section{CONCLUDING REMARKS}

Work conducted in FY91 by an interagency panel in Nuclear Electric Propulsion technology has led to findings and conclusions regarding NEP systems, technologies, and technology demonstration. Recommendations by this panel concerning the existing SP-100 space nuclear reactor program, as well as for a focused program in NEP Technology are made. The panel provided a basis for evaluating candidate NEP power/propulsion systems, began to establish requirements for a NEP systems trade study, and defined the major facility requirements of NEP. The panel identified nuclear and nonnuclear technology needs, and proposed plans for a technology program to address those needs (Doherty 1991).

\section{Acknowledgments}

The author greatly wishes to acknowledge his indebtedness to the members of the Nuclear Electric Propulsion Technology Panel: Monte Parker and Kurt Schoenberg (LANL), Wayne Schmidt (AFAL), Hans Ludewig (BNL), Jim Lake and John Dearien (INEL), Jack Mondt, John Barnett, and John Brophy (JPL), Bick Hooper (LLNL), Bob Holcomb (ORNL), Dick Widrig (PNL), Don Gallup and Frank Thome (SNL), and Jeff George, Jim Sovey, Joe Nainiger, Jim Gilland, Al Juhasz, John Dickman, and Harvey Bloomfield (LeRC). Numerous other people followed the process, contributing to its final product. Their names are too many to list here. The panel members' personal dedication to meeting attendance, subpanel 
participation, action item resolution, and to the writing of the panel final report is greatly appreciated.

\section{References}

Barnett, J. W. (1991) "Nuclear Electric Propulsion Technologies: Overview of the NASA/DOE/DOD Nuclear Electric Propulsion Workshop," in Proc. Eighth Symposium on Space Nuclear Power Systems, CONF-910116, M.S. El-Genk and M.D. Hoover, eds., American Institute of Physics, New York, 1991.

Bhattacharyya, S.K., C.S. Olsen, and R.H. Titran (1991) "Development of Nuclear Fuels and Materials for Propulsion Systems for SEI," AIAA 91-3452, September 1991.

Clark, J. S. and T. J. Miller (1991) "The NASA/DOE/DOD Nuclear Rocket Propulsion Project: FY 1991 Status," AIAA 91-3413, September 1991 .

Doherty, M. P. (1991) "Blazing the Trailway: Nuclear Electric Propulsion and Its Technology Program Plans," AIAA 91-3441, September 1991 .

Doherty, M. P. and R. S. Holcomb (1992) "A Summary and Recommendations on Nuclear Electric Propulsion Technology for the Space Exploration Initiative," NASA CP-

George, J. A. (1991) "Multimegawatt Nuclear Power Systems for Nuclear Electric Propulsion," AIAA 91-3607, September 1991.

Hack, K. J., J. A. George, and I. A. Dudzinski (1991) "Nuclear Electric Propulsion Mission Performance for Fast Piloted Mars Missions," AIAA 91-3488, September 1991.

Synthesis Group (1991) "America at the Threshold - America's Space Exploration Initiative," U.S. Government Printing Office, Washington D.C. 20402 .

Yen, C. L. and C. G. Sauer (1991) "Nuclear Electric Propulsion for Future NASA Space Science Missions," IEPC-91-035, October 1991 . 
Public reporting burden for this collection of information is estimated to average 1 hour per response, including the time for reviewing instructions, searching existing data sources, gathering and maintaining the data needed, and completing and reviewing the collection of information. Send comments regarding this burden estimate or any other aspect of this collection of information, including suggestions for reducing this burden, to Washington Headquarters Services, Directorate for information Operations and Reports, 1215 Jefferson Davis Highway, Suite 1204, Artington, VA 22202-4302, and to the Office of Managernent and Budget, Paperwork Reduction Project (0704-0188), Washington, DC 20503.

\begin{tabular}{|l|c|c|}
\hline 1. AGENCY USE ONLY (Leave blank) & $\begin{array}{c}\text { 2. REPORT DATE } \\
1992\end{array}$ & $\begin{array}{r}\text { 3. REPORT TYPE AND DATES COVERED } \\
\text { Technical Memorandum }\end{array}$ \\
\hline
\end{tabular}

\section{TITLE AND SUBTITLE}

Nuclear Electric Propulsion Technology Panel Findings and Recommendations

6. AUTHOR(S)

Michael P. Doherty

\section{PERFORMING ORGANIZATION NAME(S) AND ADDRESS(ES)}

National Aeronautics and Space Administration

Lewis Research Center

Cleveland, Ohio 44135-3191

9. SPONSORING/MONITORING AGENCY NAMES(S) AND ADDRESS(ES)

National Aeronautics and Space Administration

Washington, D.C. 20546-0001
5. FUNDING NUMBERS

WU-593-72

8. PERForming ORganization REPORT NUMBER

E- 6870

10. SPONSORING/MONITORING AGENCY REPORT NUMBER

NASA TM- 105547

11. SUPPLEMENTARY NOTES

Prepared for the Ninth Symposium on Space Nuclear Power Systems, Albuquerque, New Mexico. Responsible person, Michael P. Doherty, (216) 433-7092.

12a. DISTRIBUTION/AVAILABILITY STATEMENT

12b. DISTRIBUTION CODE

Unclassified - Unlimited

Subject Categories 16 and 20

13. ABSTRACT (Maximum 200 words)

Summarized in this paper are the findings and recommendations of a triagency (NASA/DOE/DOD) panel on Nuclear Electric Propulsion (NEP) Technology. NEP has been identified as a candidate nuclear propulsion technology for exploration of the Moon and Mars as part of the Space Exploration Initiative (SEI). The findings are stated in the areas of system and subsystem considerations, technology readiness, and ground test facilities. Recommendations made by the panel are summarized concerning (1) existing space nuclear power and propulsion programs and (2) the proposed multiagency NEP technology development program.

\section{SUBJECT TERMS}

Nuclear electric propulsion; NEP; Technology; Missions; Systems; Facilities

17. SECURITY CLASSIFICATION
OF REPORT
Unclassified

NSN 7540-01-280-5500
18. SECURITY CLASSIFICATION OF THIS PAGE Unclassified
19. SECURITY CLASSIFICATION OF ABSTRACT Unclassified
15. NUMBER OF PAGES 10

16. PRICE CODE

$\mathrm{AO2}$

20. LIMITATION OF ABSTRACT 